\title{
Patient-reported financial barriers to adherence to treatment in neurology
}

\author{
Lidia MVR Moura' \\ Eli L Schwamm' \\ Valdery Moura Junior' \\ Michael P Seitz' \\ Daniel B Hoch' \\ John $\mathrm{Hsu}^{2,3}$ \\ Lee H Schwamm'
}

'Department of Neurology, ${ }^{2}$ Mongan Institute for Health Policy, Massachusetts General Hospital, ${ }^{3}$ Department of Medicine and Department of Health Care Policy, Harvard Medical School, Boston, MA, USA
Correspondence: Lidia MVR Moura Department of Neurology, Wang 720 Neurology, Massachusetts General Hospital, 55 Fruit Street, Boston, MA 02114, USA

Tel + I 6177263311

Fax+I61772465I3

Email lidia.moura@mgh.harvard.edu
This article was published in the following Dove Press journal:

ClinicoEconomics and Outcomes Research

17 November 2016

Number of times this article has been viewed

Objective: Many effective medical therapies are available for treating neurological diseases, but these therapies tend to be expensive and adherence is critical to their effectiveness. We used patient-reported data to examine the frequency and determinants of financial barriers to medication adherence among individuals treated for neurological disorders.

Patients and methods: Patients completed cross-sectional surveys on iPads as part of routine outpatient care in a neurology clinic. Survey responses from a 3-month period were collected and merged with administrative sources of demographic and clinical information (eg, insurance type). We explored the association between patient characteristics and patientreported failure to refill prescription medication due to cost in the previous 12 months, termed here as "nonadherence".

Results: The population studied comprised 6075 adults who were presented between July and September 2015 for outpatient neurology appointments. The mean age of participants was 56 (standard deviation: 18) years, and 1613 (54\%) were females. The patients who participated in the surveys $(2992,49 \%)$ were comparable to nonparticipants with respect to gender and ethnicity but more often identified English as their preferred language ( $94 \%$ vs $6 \%, p<0.01)$. Among respondents, $9.8 \%(n=265)$ reported nonadherence that varied by condition. These patients were more frequently Hispanic ( $16.7 \%$ vs $9.8 \%$ white, $p=0.01)$, living alone $(13.9 \%$ vs $8.9 \%$ cohabitating, $p<0.01)$, and preferred a language other than English ( $15.3 \%$ vs $9.4 \%, p=0.02)$.

Conclusion: Overall, the magnitude of financial barriers to medication adherence appears to vary across neurological conditions and demographic characteristics.

Keywords: outcomes, adherence, cost

\section{Introduction}

There is a growing armamentarium of effective medical therapies to treat neurological diseases. ${ }^{1,2}$ National guidelines have discussed ten US Food and Drug Administration (FDA)-approved disease-modifying therapies for multiple sclerosis, >20 FDA-approved antiepileptic drugs for seizure prophylaxis, and 23 drugs involved in stroke prevention, including novel oral anticoagulants. ${ }^{3-5}$ Most of these therapies are expensive and adherence is critical to their effectiveness. ${ }^{6-8}$

Medication adherence depends on many factors, including affordable access to drugs, which varies by drug type and insurance-benefit design. For instance, Medicare beneficiaries obtain outpatient drug coverage through the Part D program, which is administered by private insurance plans, i.e., Part D drug plans. The formulary protections of these plans apply to formulary inclusion, but not tier placement. The resulting differences in out-of-pocket payments can be challenging for beneficiaries with limited 
incomes or impaired cognition. ${ }^{9}$ In addition, since adherence depends mainly on patient reporting and perception, it has been demonstrated that many patients who claim to have been adherent to their medications are in fact not. ${ }^{10,11}$ According to a recent study on therapeutic drug monitoring in consecutive emergency hospital admissions for seizures, $>40 \%$ of nonadherent patients claimed to have been adherent when further asked about medication failure. ${ }^{12}$

Medication nonadherence has been shown to seriously hurt health outcomes in neurology, and hence efforts to understand the causes and solutions to this problem have become increasingly important. Some studies have shown a moderate association between drug choice, adherence, and satisfaction with treatment. ${ }^{7,13}$ Previous studies of medication nonadherence in neurology have been limited to population-wide databases and reliable claims-based algorithms. ${ }^{14-24}$ These large-scale approaches to the evaluation of medication adherence using retrospective electronic health records (EHRs) abstraction or claims data have missed critical information and fallen short in representing the realworld complexity. ${ }^{25}$ In an effort to capture more accurate, specific, and informative data on medication nonadherence, systematic collection of patient-reported outcomes offers great promise. ${ }^{26,27}$

The term "patient-reported outcomes" refers to data directly collected from patients such as self-administered surveys and other attempts to quantify patients' behavior and their subjective experience of health. Patient-reported data have been shown to correlate with and augment more typical clinical measurements, proving useful in the assessment of treatment outcomes and determinants of health. ${ }^{28-31}$

This study examined the frequency and determinants of financial barriers to medication adherence among individuals treated for neurological disorders using patient-reported data.

\section{Patients and methods}

\section{Participants}

This study was a retrospective review of data collected as part of a quality improvement project implemented in Neurology Ambulatory clinical practices that began in July 2015 and continues to date. Since July 2015, all ambulatory neurology patients in the outpatient waiting room aged 18+ years have been offered an iPad survey upon arrival at the office, except for unaccompanied nonEnglish speakers, whose eligibility was determined by front desk staff based on the patient's observed inability to understand very simple survey directions. The front desk staff had received standard institutional training to determine patients' ability to read and sign check-in-related documents (eg, insurance-driven pre-office forms). All patients were given the opportunity to verbally opt out of the survey and were reminded that the quality of their care would not be adversely affected by survey completion. Patients who arrived late for appointments or had other essential tasks to complete prior to the physician visit were at times unable to complete the survey prior to the end of the office visit. Although longitudinal data were captured for patients with several visits during this period, only the first visit was included in the analysis. ${ }^{7,32,33}$

\section{Procedures and measurements}

This study combines information from the survey merged by deterministic linkage using the medical record number to administrative and clinical data gathered using a Research Patient Data Registry (RPDR) query tool.

\section{Survey}

In ambulatory neurology clinics, patients were checked in by front desk staff before being seen by the provider. After determining patient appropriateness, the front desk staff handed patients an iPad tablet pre-loaded with the survey questions. Patients completed the survey in the waiting room. Before beginning, they were prompted to read and agree to an informed consent disclaimer, which they signed on the Apple iPad2 (Apple, CA, USA) screen. A report summarizing the patients' survey responses became available in the EHR immediately upon completion, and providers were encouraged to review this information with the patient.

The survey had four parts - an introduction, demographic questions, and the medication adherence question, "How often in the past 12 months did you decide not to fill or refill your prescription because the medicines cost too much?" with the answers "often", "sometimes", "never", and "prefer not to answer". After this question, the survey included an additional questionnaire to measure global health function, which is not the focus of this article and is detailed in the Supplementary materials.

\section{RPDR query tool}

We anticipated that not all patients would be able to participate in the survey. To determine the primary predictors of participation and examine the potential for selection bias, we gathered additional demographic information using the Partners Healthcare Clinical data registry for all arriving patients (both participating and nonparticipating in the survey) seen in the Ambulatory Neurology clinics during the study time frame. The RPDR is a clinical data registry that aggregates data from sources throughout the Partners 
Healthcare System (PHS), including the medical record, reports, claims, and administrative systems. Queried variables included age, gender, preferred language, insurance status, ethnicity, marital status, and clinic type (eg, general neurology vs subspecialty area).

Results of the RPDR query identified patients scheduled for an ambulatory neurology clinical visit from July 2015 to September 2015. A member of the study staff reviewed the RPDR query output to exclude ineligible patients or encounters. Eligible encounters were the patients $>18$ years of age seen at the neurology outpatient clinic (main campus only), who had a first visit or were established patients who came for a follow-up visit within the study time frame (subsequent visits were excluded). There were 6075 eligible visits.

\section{Statistical analysis}

We defined cost-related medication nonadherence as an answer of "often" or "sometimes" to the question "How often in the past 12 months did you decide not to fill or refill a prescription because the medicines cost too much?".

We performed univariate comparisons of the baseline characteristics of the adherence groups using two-group twosided $t$-tests for continuous variables and chi-square tests for categorical variables. In multivariable analysis, we utilized logistic regression models to assess the associations between sociodemographic and clinical characteristics associated with the report of cost-related medication nonadherence. The independent variables were selected based on prior knowledge and examination of the distribution of the univariate analysis. Conservatively, no step-wise approach was used.

To address the potential for selection bias in our respondents, we performed univariate analysis of covariates associated with survey participation (participants vs nonparticipants, including age, gender, ethnicity, preferred language, insurance type, marital status, and clinic type).

We used SAS Studio ${ }^{\circledR}$, version 9.4 for statistical analysis.

This study was conducted under a protocol approved by the Partners Healthcare Institutional Review Board.

\section{Results}

A total of 2992 out of 6075 patients participated in the survey and 2716 fully completed the survey questions, yielding a participation rate of $49 \%$ and a completion rate of $45 \%$ (Figure S1). The mean age of participants was 56 (SD: 18) years and 1613 (54\%) were females. Respondents were comparable to nonrespondents with respect to gender and ethnicity. Survey responders more often identified English as their preferred language $(90.6 \%, p=0.02$; Table S1).
Among the participants, 9.8\% $(n=265)$ of patients reported cost-related medication nonadherence. More specifically, nonadherent patients "often" (40 or $15.1 \%$ ) or "sometimes" (225 or $84.9 \%$ ) failed to fill or refill a prescription (Figure 1).

Table 1 summarizes the distribution of sociodemographic indicators among nonadherent vs adherent patients. Patients who reported cost-related nonadherence were younger (mean age: $53 \pm 16$ years vs $56 \pm 18$ years, $p<0.01)$, more often Hispanic $(16.7 \%$ vs $9.8 \%, p<0.01)$, had a native language that was not English ( $22 \%$ vs $9.4 \%, p=0.02)$, and were not currently partnered (single, separated, divorced, or widowed vs married; $11.9 \%$ vs $8.5 \%, p<0.01)$.

In multivariable analysis, care in subspecialty clinics, compared to general neurology clinic as the reference, was associated with higher rates of patient-reported nonadherence. Stroke clinical patients had twice the odds ratio (OR) of nonadherence (OR $=2.09,95 \% \mathrm{CI}$ : $1.05-4.16)$, and memory disorder clinical patients had more than threefold increase (OR $=3.73$, 95\% CI: 1.31-10.59; Figure S2). A sensitivity analysis using both marital status and cohabitation in a multivariable logistic regression did not significantly impact the reported results.

\section{Discussion}

We have presented a cross-sectional study of cost-related medication nonadherence to use in a patient-reported survey conducted in a large cohort of neurology patients. Our results suggest that the prevalence of financial barriers to medication adherence is modest $(<10 \%)$. These findings were consistent with those presented in the study of Campbell et al, ${ }^{34}$ who found that trouble affording medications was the fourth leading reason for medication nonadherence among elderly patients.

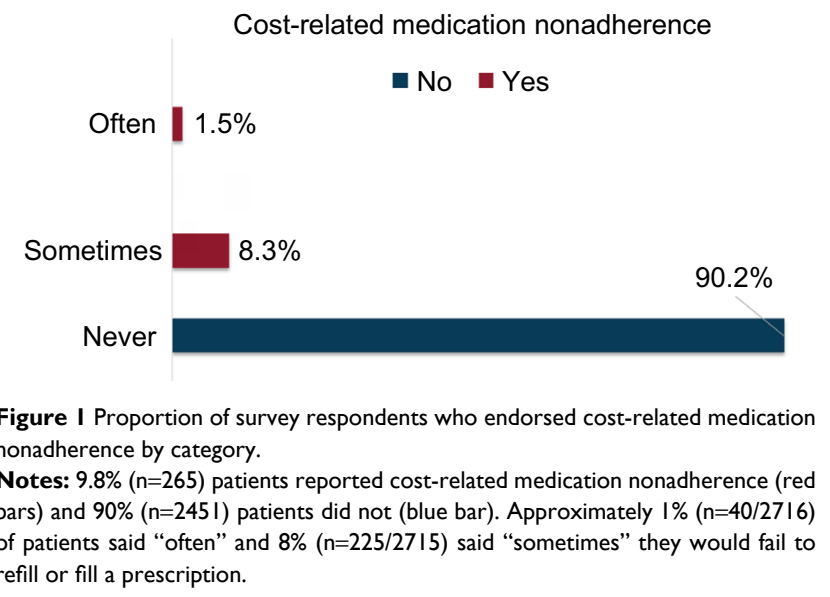


Table I Demographic and clinical characteristics of patients with vs without cost-related nonadherence to medications

\begin{tabular}{|c|c|c|c|}
\hline & \multicolumn{2}{|c|}{ Cost-related non-adherence } & \multirow[t]{2}{*}{$p$-Value } \\
\hline & No & Yes & \\
\hline $\begin{array}{l}\text { Number of patients, } \\
\mathrm{N}=2716(\%)\end{array}$ & $\mathrm{N}=245 \mathrm{I}(90)$ & $\mathrm{N}=265(10)$ & \\
\hline Mean age in years (SD) & $56(18.33)$ & $53(16)$ & 0.001 \\
\hline Gender (\%), N=27I5 & & & 0.02 \\
\hline Male & II 43 (9I.7) & $104(8.34)$ & \\
\hline Preferred language (\%) & & & 0.02 \\
\hline English & $2329(90.6)$ & $243(9.4)$ & \\
\hline Ethnicity (\%), $N=1687$ & & & 0.01 \\
\hline Non-Hispanic & $1386(90.2)$ & $|5|(9.8)$ & \\
\hline $\begin{array}{l}\text { Marital status (\%), } \\
N=2603\end{array}$ & & & 0.004 \\
\hline $\begin{array}{l}\text { Single, separated, } \\
\text { divorced, widowed }\end{array}$ & $943(88.1)$ & $128(11.9)$ & \\
\hline Married & $|40|(9 \mid .5)$ & $|3|(8.5)$ & \\
\hline Cohabitation (\%) & & & 0.004 \\
\hline Single & $372(86.1)$ & 60 (13.9) & \\
\hline Shared & 2022 (91.I) & $197(8.9)$ & \\
\hline Prefer not to answer & $57(87.7)$ & $8(12.3)$ & \\
\hline Education (\%) & & & 0.08 \\
\hline Grade school & $91(90.1)$ & $10(9.9)$ & \\
\hline High school or GED & $853(89.8)$ & $97(10.2)$ & \\
\hline Bachelor's degree & $739(89.7)$ & $85(10.3)$ & \\
\hline $\begin{array}{l}\text { Master's degree or } \\
\text { higher }\end{array}$ & $667(92.4)$ & $55(7.6)$ & \\
\hline Prefer not to answer & $101(84.9)$ & $18(15.1)$ & \\
\hline Insurance status (\%) & & & 0.38 \\
\hline Public insurance & $833(91.0)$ & $83(9.0)$ & \\
\hline Private insurance & $1618(89.9)$ & $182(10.1)$ & \\
\hline $\begin{array}{l}\text { Employment (\%), } \\
\mathrm{N}=27 / 5\end{array}$ & & & 0.11 \\
\hline Employed full time & 801 (89.7) & $92(10.3)$ & \\
\hline Employed part time & $264(90.4)$ & $28(9.6)$ & \\
\hline Retired & $916(92.1)$ & 79 (7.9) & \\
\hline Unemployed & $373(88.0)$ & $51(12.0)$ & \\
\hline Prefer not to answer & $97(87.4)$ & $14(12.6)$ & \\
\hline $\begin{array}{l}\text { Survey respondent (\%), } \\
N=27 \mid 5\end{array}$ & & & 0.01 \\
\hline Patient & $2065(89.7)$ & $238(10.3)$ & \\
\hline Proxy & $386(93.7)$ & $26(6.3)$ & \\
\hline Clinic type (\%) & & & $<0.0001$ \\
\hline Ataxia & $30(93.8)$ & $2(6.2)$ & \\
\hline Epilepsy & $163(94.2)$ & $10(5.8)$ & \\
\hline General neurology & $1060(88.6)$ & $137(\mid 1.4)$ & \\
\hline Memory disorders & $225(96.6)$ & $8(3.4)$ & \\
\hline Movement disorders & $395(92.5)$ & $32(7.5)$ & \\
\hline Motor neuron disorders & $49(89.1)$ & $6(10.9)$ & \\
\hline $\begin{array}{l}\text { Neurobehavioral } \\
\text { disorders }\end{array}$ & $130(85.0)$ & $23(15.0)$ & \\
\hline Sleep disorders & $166(83.4)$ & $33(16.6)$ & \\
\hline Stroke & $233(94.3)$ & I4 (5.7) & \\
\hline
\end{tabular}

Notes: The comparison between the group of patients that reported cost-related medication non-adherence (Yes) and the group of patients that did not (No). We used two-sided $t$-tests to calculate $p$-values to compare the mean values of patient age between the groups. We used the chi-squared test of independence to calculate the $p$-values to test whether the categorical variables were associated with increased rates of adherence.

Abbreviation: GED, General Education Diploma.
However, the comparison of our cost-related non-adherence rates with the current literature is limited by the general lack of congruence in the way adherence is measured and reported. Most other medication adherence studies have either evaluated patients in controlled settings with small sample sizes or used claims data to measure patient prescription refills. In comparison, our survey describes the patient report of the burden of financial barriers to medication adherence. ${ }^{35,36}$

In addition, to reduce potential for both recall and interviewer bias, we collected data from patients immediately before their clinical visits. We believe that collecting data from patients immediately before their clinical visits yielded more accurate results because the patients were already prompted to think about their health problems and medications in use. Also, having to complete the survey in the waiting room allowed the patients to have ready access to staff members and clarify the meaning of any question they found hard to interpret. In comparison, this would not be possible in a paper-based form sent out after clinic. ${ }^{37-41}$ Of note, our participation and completion rates ( $49 \%$ and $45 \%$, respectively) were similar to the rates obtained in previous similar studies. ${ }^{42-46}$

A second interesting finding was that patients seen at the memory disorders clinic, which includes primarily patients with Alzheimer's disease and related dementias who were almost always accompanied by a care giver, were especially vulnerable to financial barriers to medication adherence, even after adjusting for pertinent socioeconomic factors. This finding is particularly concerning because these patients tend to be older, and medication adherence by older patients is lower compared to younger patients due to increased side effects as well. ${ }^{47-49}$ These older- and cognitively impaired adults are clinically vulnerable due to concurrent medical illnesses and drug interactions. ${ }^{47-49}$ Studies have shown that the number and types of co-morbidities, such as depression, are predictors of cost-related nonadherence. ${ }^{36,37}$ This is especially striking since most of these patients are Medicare eligible and so would not be expected to have large out-of-pocket expenses for many tests, procedures, or hospitalizations.

Observational retrospective studies using claims data (prescription fills) have suggested that drug-benefit design and tier strategies (i.e., prescription drug coverage) may also affect adherence to treatment. ${ }^{50}$ Adding complexity to this problem, McWilliams et $\mathrm{al}^{9}$ showed that Medicare beneficiaries with low cognitive function were less responsive to the generosity of Medicare Advantage benefits in their decisions (i.e., multiple and complex insurance plan benefit choices negatively impacted seniors with impaired decision making). Our study findings build upon the existing literature 
and highlight the complex interaction of multiple socioeconomic and clinical factors in cost-related nonadherence. ${ }^{35}$

In this study, patients from socially disadvantaged backgrounds, such as Hispanics and non-English speakers, also appear to be more likely to report having financial barriers to medication adherence. ${ }^{51}$ Our study supports other groups that have presented data on how people of lower socioeconomic status and ethnic minorities report higher rates of cost-related medication nonadherence. . $^{37,47,52-57}$

While many studies focused on examining the adherence to a specific medication, we asked a broad question about any medication, which allowed for a cross-clinic comparison. ${ }^{58}$ In the case of patients with Alzheimer's disease in our memory disorders clinic, our study findings remain consistent with studies about the recent rising costs of neurology prescription drugs, which ultimately indicates more out-of-pocket spending for this population. ${ }^{5}$ For example, an analysis of Medicare Part D data revealed that neurologists comprised only $1.2 \%$ of prescribing providers but expenditures with neurology-prescribed medications were the third highest of all specialties. Medications for multiple sclerosis, epilepsy, and Alzheimer's disease and related dementias were the major drivers of the exceptional costs ( $\$ 5$ billion in 2013). ${ }^{5}$

Finally, this study is aligned with the existing literature that suggests that patient reporting and the linking of multiple sources of data have been shown to improve the accuracy of research findings. ${ }^{59,60}$

This study had many important limitations. Most notably, the trade-off in asking a broad medication adherence question and absence of data from chart abstraction is that we may not have captured the specific medication that is the principal reason for the financial barrier in each clinical scenario. For instance, aspirin is an important medication prescribed for patients with stroke. This medication is relatively of low cost and is classified as Tier 1, designating medications that are largely covered, according to the most common insurance policies. For patients with stroke, we believe that the culprit might be the related medications often prescribed in patients with stroke, such as anticoagulants and medications for hypertension, hyperlipidemia, and pain management. ${ }^{58,61}$

In addition, other broad wordings that serve as a limitation of our study were such as the categorical scale with frequency options (eg, "often", "sometimes", and "never"). The meanings of these frequency words can vary among individuals. Perhaps, an open-ended question could yield a more specific measurement (eg, "How many days in a month would you miss a medication?"). However, the likelihood that a patient would be able to provide an accurate numerical value with respect to adherence over the past 12 months would be low.
Therefore, we considered categorical scales easier to respond and opted to use simple frequency words.

A second major limitation was that we were unable to distinguish between patients who declined to participate and patients who were not approached, due to the aforementioned exclusion criteria and administrative errors. The absence of these data prevents further characterization of potentially confounding participant vs nonparticipant differences. In addition, we excluded unaccompanied non-English speakers and unaccompanied patients with severe cognitive impairment. Both the criteria were determined after a patient-handed survey based on self-reported or observed inability to follow basic survey directions. Also, 275 patients (9\%) started the survey but did not complete the medication adherence question. The reasons for leaving the survey incomplete include the early call from the treating physician (eg, when there is $<10$ minutes of waiting time from check-in to the encounter with the physician), fatigue (eg, patients get tired and give up), and distractions (eg, patients answer phone calls and leave the survey aside). Another limitation that exists with the study population is that the research team did not consider other impairments, such as visual impairment, as one of the exclusion criteria due to the fact that patients were likely to visit with a designated proxy. Because the patients were self-answering the survey in the context of a busy neurology clinic, we were unable to track specific reasons for survey exclusion and incompletion.

This study has limited generalizability to nonacademic medical centers as is common to many similar studies. ${ }^{11,22}$ However, it is hoped that the findings are more generalizable due to the high participation and completion rates. We did not identify patients who were nonadherent because of nonfinancial reasons, and therefore the comparison arm of our analysis includes some patients who were nonadherent due to other reasons.

Next, this study did not prospectively capture adherence following the prescription of a specific medication, making causal association in our study impossible. The clinical value of our study was demonstrated in the secondary analysis. As outlined earlier, this study made note of a potential association between patients being seen in certain clinics that may prescribe more expensive medications, such as those for patients with Alzheimer's disease and related dementias, suggesting that they may have a higher cost-sharing burden.

Finally, residual measured and unmeasured confounding may exist, such as the cost per drug tier in each patient's insurance coverage formulary. We would expect that the patients with cost-related nonadherence would have been most often prescribed medications in the highest cost tier, as described in previous studies. ${ }^{62}$ However, we were not able to examine if nonadherence was related to drug tier and co-pay as we did 
not have reliable access to each patient's pharmacy benefit to determine these interactions.

Despite these limitations, this study offers opportunities to improve outcomes in neurology patients through medication adherence and drive health policy in neurology. There are many possible future studies and solutions to the issues we have outlined. 1) Patients could be encouraged to reduce their medication costs by requesting generic medications or using mail order pharmacies. 2) More assistance for patients in navigating health insurance and therapeutic choices might reduce nonadherence to medication regimens among patients with neurological conditions. 3) Value-based drug pricing (varying payments for medications based on outcomes or magnitude of clinical benefits) may be another means of engaging patients, physicians, and payers toward improving adherence and outcomes.

Our study also sought to improve the discussions between patients and treating physicians about prices of medications. We present the medication adherence question to the patients before their visit in order to prompt the patients to discuss any prescription filling problems with the treating physician during the encounter. However, patients still have difficulty starting this conversation and may only realize the amount of co-pay when they go to pick up their refill after the clinical visit. We encourage quality improvement strategies, such as using electronic notifications of answers to the cost-related nonadherence question, in order to encourage the physicians to incite these discussions about financial issues. Future studies should also integrate patient-reported information into insurance-benefit designs in order to measure the actual ratio of adherence to out-of-pocket spending, per patient and by treatment period.

\section{Conclusion}

This study suggests that while the overall level of poor adherence due to costs is limited, cost-related barriers to medication adherence appear to be concentrated among the most cognitively- and socioeconomically vulnerable patients. Multiple strategies are needed to prospectively identify these vulnerable patients and to alter prescribing practices to enhance affordability and thereby long-term efficacy.

\section{Acknowledgments}

LMVRM is the recipient of a 2015-2016 Clinical Research Fellowship sponsored by the American Brain Foundation. LMVRM is a neurologist and health services researcher married to co-author VMJ who is a database analyst and $\mathrm{PhD}$ candidate in health care analytics. ELS is a former research student at the MGH Neurovalue laboratory. LHS is a senior health services researcher, mentor of LMVRM, and father of ELS. JH is supported by grants from NIH and AHRQ (1R01 CA164023, 2P01AG032952, R01 HD075121, R01 MH104560, and R01HS023128). LS is supported by grants from NINDS (5U01NS077179-02 and U10 NS086729) and PCORI (CE-1304-7073, CDRN1306-04608, IHS-1310-07420, and P50 NS051343). There is no study funding.

\section{Author contributions}

LMVRM conceptualized and designed the study. LMVRM, ELS, and VMJ performed data collection. LMVRM and VMJ performed the database management and statistical analysis. LMVRM, JH, and VMJ drafted the original manuscript. LMVRM, JH, MPS, DBH, and LHS significantly reviewed and revised the manuscript. All authors contributed toward data analysis, drafting and critically revising the paper and agree to be accountable for all aspects of the work.

\section{Disclosure}

The authors report no conflicts of interest in this work.

\section{References}

1. Roberts K, Costelloe D, Hutchinson M, Tubridy N. What difference does a neurologist make in a general hospital? Estimating the impact of neurology consultations on in-patient care. Ir J Med Sci. 2007;176(3):211-214.

2. Panayiotopoulos CP, Benbadis SR, Covanis A, et al. Efficacy and tolerability of the new antiepileptic drugs I: treatment of new onset epilepsy: report of the Therapeutics and Technology Assessment Subcommittee and Quality Standards Subcommittee of the American Academy of Neurology and the American Epileps. Neurology. 2005;64(1):172-174.

3. Mangas A, Coveñas R, Geffard M. New drug therapies for multiple sclerosis. Curr Opin Neurol. 2010;23(3):287-292.

4. Fargo K. Alzheimer's Association report: 2014 Alzheimers disease facts and figures. Alzheimers Dement. 2014;10(2):e47-e92.

5. De Lott LB, Burke JF, Kerber KA, Skolarus LE, Callaghan BC. Medicare part D payments for neurologist-prescribed drugs. Neurology. 2016;86(16):1491-1498.

6. Atkinson MJ, Sinha A, Hass SL, et al. Validation of a general measure of treatment satisfaction, the treatment satisfaction questionnaire for medication (TSQM), using a national panel study of chronic disease. Health Qual Life Outcomes. 2004;2:12.

7. Sweileh WM, Ihbesheh MS, Jarar IS, et al. Self-reported medication adherence and treatment satisfaction in patients with epilepsy. Epilepsy Behav. 2011;21(3):301-305.

8. Brown MT, Bussell JK. Medication adherence: who cares? Mayo Clin Proc. 2011;86(4):304-314.

9. McWilliams JM, Afendulis CC, McGuire TG, Landon BE. Complex medicare advantage choices may overwhelm seniors - especially those with impaired decision making. Health Aff (Millwood). 2011;30(9):1786-1794.

10. McAuley JW, McFadden LS, Elliott JO, Shneker BF. An evaluation of self-management behaviors and medication adherence in patients with epilepsy. Epilepsy Behav. 2008;13(4):637-641.

11. McAuley JW, Passen N, Prusa C, Dixon J, Cotterman-Hart S, Shneker BF. An evaluation of the impact of memory and mood on antiepileptic drug adherence. Epilepsy Behav. 2015;43:61-65. 
12. Lie IA, Hoggen I, Samsonsen C, Brodtkorb E. Treatment non-adherence as a trigger for status epilepticus: an observational, retrospective study based on therapeutic drug monitoring. Epilepsy Res. 2015;113:28-33.

13. Gabr WM, Shams MEE. Adherence to medication among outpatient adolescents with epilepsy. Saudi Pharm J. 2015;23(1):33-40.

14. Couto JE, Panchal JM, Lal LS, et al. Geographic variation in medication adherence in commercial and medicare part D populations. J Manag Care Spec Pharm. 2014;20(8):834-842.

15. Tsiropoulos I, Gichangi A, Andersen M, Bjerrum L, Gaist D, Hallas J. Trends in utilization of antiepileptic drugs in Denmark. Acta Neurol Scand. 2006;113(6):405-411.

16. Franchi C, Giussani G, Messina P, et al. Validation of healthcare administrative data for the diagnosis of epilepsy. J Epidemiol Community Health. 2013;67(12):1019-1024.

17. Reid AY, Germaine-smith CS, Liu M, et al. Development and validation of a case definition for epilepsy for use with administrative health data. Epilepsy Res. 2012;102(3):173-179.

18. Bakaki PM, Koroukian SM, Jackson LW, Albert JM, Kaiboriboon K. Defining incident cases of epilepsy in administrative data. Epilepsy Res. 2013;106(1-2):273-279.

19. Christensen J, Vestergaard M, Pedersen MG, Pedersen CB, Olsen J, Sidenius P. Incidence and prevalence of epilepsy in Denmark. Epilepsy Res. 2007;76(1):60-65.

20. Christensen J, Vestergaard M, Olsen J, Sidenius P. Validation of epilepsy diagnoses in the Danish National Hospital Register. Epilepsy Res. 2007;75(2-3):162-170.

21. Tu K, Wang M, Jaakkimainen RL, et al. Assessing the validity of using administrative data to identify patients with epilepsy. Epilepsia. 2014;55(2):335-343.

22. Betjemann JP, Josephson SA, Lowenstein DH, Burke JF. Trends in status epilepticus - related hospitalizations and mortality redefined in US practice over time. JAMA Neurol. 2016;72(6):650-655.

23. Faught E, Martin R, Funkhouser E, Foushee R, Kim Y, Cohen N. Incidence and prevalence of epilepsy among older US medicare beneficiaries. Neurology. 2012;78(7):448-453.

24. Tan M, Wilson I, Braganza V, et al. Epilepsy \& behavior development and validation of an epidemiologic case definition of epilepsy for use with routinely collected Australian health data. Epilepsy Behav. 2015;51:65-72.

25. Thurman DJ, Beghi E, Begley CE, et al. Standards for epidemiologic studies and surveillance of epilepsy. Epilepsia. 2011;52(suppl 7):2-26.

26. Cella D, Yount S, Rothrock N, et al. The patient-reported outcomes measurement information system (PROMIS): progress of an NIH roadmap cooperative group during its first two years. Med Care. 2007;45(5 suppl 1):S3-S11.

27. Stafford M, Gavriel S, Lloyd A. Patient-reported outcomes measurements in epilepsy. Expert Rev Pharmacoecon Outcomes Res. 2007; 7(4):373-384.

28. Fayers P, Machin D. Quality of Life: The Assessment, Analysis and Interpretation of Patient-reported Outcomes. 2nd ed. New York: John Wiley \& Sons; 2013

29. Stewart JC, Cramer SC. Patient-reported measures provide unique insights into motor function after stroke. Stroke. 2013;44(4):1111-1116.

30. Shei A, Woolley J, Desai P, et al. Description of prophylactic drug utilization patterns in migraine patients. Value Health. 2015;18(3):A285

31. Li F, Harmer P, Liu Y, et al. A randomized controlled trial of patientreported outcomes with tai chi exercise in Parkinson's disease. Mov Disord. 2014;29(4):539-545.

32. Liu J, Liu Z, Ding H, Yang X. Adherence to treatment and influencing factors in a sample of Chinese epilepsy patients. Epileptic Disord. 2013;15(3):289-294.

33. Fung V, Huang J, Brand R, Newhouse JP, Hsu J. Hypertension treatment in a medicare population: adherence and systolic blood pressure control. Clin Ther. 2007;29(5):972-984.

34. Campbell NL, Zhan J, Tu W, et al. Self-reported medication adherence barriers among ambulatory older adults with mild cognitive impairment. Pharmacotherapy. 2016;36(2):196-202.

35. Lee M, Salloum RG. Racial and ethnic disparities in cost-related medication non-adherence among cancer survivors. J Cancer Surviv. 2015;10(3):534-544.
36. Kennedy JJ, Maciejewski M, Liu D, Blodgett E. Cost-related nonadherence in the medicare program: the impact of part D. Med Care. 2011;49(5):522-526.

37. Blanchard J, Madden JM, Ross-Degnan D, Gresenz CR, Soumerai SB. The relationship between emergency department use and cost-related medication nonadherence among medicare beneficiaries. Ann Emerg Med. 2013;62(5):475-485.

38. Patel MR, Kruger DJ, Cupal S, Zimmerman MA. Effect of financial stress and positive financial behaviors on cost-related nonadherence to health regimens among adults in a community-based setting. Prev Chronic Dis. 2016;13(3):E46.

39. Zivin K, Ratliff S, Heisler MM, Langa KM, Piette JD. Factors influencing cost-related nonadherence to medications in older adults: a conceptually based approach (in press). Value Health. 2009;13(4):338-345.

40. Bakk L. Racial/ethnic differences in cost-related nonadherence and medicare part D: a longitudinal comparison. J Health Care Poor Underserved. 2015;26(4):1132-1148.

41. Blumberg DM, Prager AJ, Liebmann JM, Cioffi GA, De Moraes CG. Cost-related medication nonadherence and cost-saving behaviors among patients with glaucoma before and after the implementation of medicare part D. JAMA Ophthalmol. 2015;133(9):985-996.

42. Parker MJ, Manan A, Urbanski S. Prospective evaluation of direct approach with a tablet device as a strategy to enhance survey study participant response rate. BMC Res Notes. 2012;5(1):605.

43. Barentsz MW, Wessels H, van Diest PJ, et al. Tablet, web-based, or paper questionnaires for measuring anxiety in patients suspected of breast cancer: patients' preferences and quality of collected data. J Med Internet Res. 2014;16(10):e239.

44. Turney BW, Reynard JM. Obtaining patient feedback in an outpatient lithotripsy service is facilitated by use of a touch-screen tablet (iPad ${ }^{\mathrm{TM}}$ ) survey. Urolithiasis. 2014;42(4):317-321.

45. Wofford JL, Campos CL, Jones RE, Stevens SF. Real-time patient survey data during routine clinical activities for rapid-cycle quality improvement. JMIR Med Inform. 2015;3(1):e13.

46. Suzuki E, Mackenzie L, Sanson-Fisher R, et al. Acceptability of a touch screen tablet psychosocial survey administered to radiation therapy patients in Japan. Int J Behav Med. 2016;23(4):485-491.

47. Ettinger AB, Manjunath R, Candrilli SD, Davis KL. Prevalence and cost of nonadherence to antiepileptic drugs in elderly patients with epilepsy. Epilepsy Behav. 2009;14(2):324-329.

48. Johannessen SI, Landmark CJ. Antiepileptic drug interactions principles and clinical implications. Curr Neuropharmacol. 2010;8(3): 254-267.

49. Perucca E, Berlowitz D, Birnbaum A, et al. Pharmacological and clinical aspects of antiepileptic drug use in the elderly. Epilepsy Res. 2006; 68(suppl 1):S49-S63.

50. Huskamp HA, Deverka PA, Epstein AM, Epstein RS, McGuigan KA, Frank RG. The effect of incentive-based formularies on drug utilization and spending. N Engl J Med. 2003;349(23):2224-2232.

51. Kim G, Aguado Loi CX, Chiriboga DA, Jang Y, Parmelee P, Allen RS. Limited English proficiency as a barrier to mental health service use: a study of Latino and Asian immigrants with psychiatric disorders. J Psychiatr Res. 2011;45(1):104-110.

52. Frankenfield DL, Wei II, Anderson KK, Howell BL, Waldo D, Sekscenski E. Prescription medication cost-related non-adherence among medicare CAHPS respondents: disparity by Hispanic ethnicity. J Health Care Poor Underserved. 2010;21(2):518-543.

53. Ettinger AB, Good MB, Manjunath R, Edward Faught R, Bancroft $\mathrm{T}$. The relationship of depression to antiepileptic drug adherence and quality of life in epilepsy. Epilepsy Behav. 2014;36:138-143.

54. Montouris G, Hohler AD. Cultural barriers to medication adherence in epilepsy. Continuum (Minneap Minn). 2016;22:266-269.

55. Shallcross AJ, Becker DA, Singh A, et al. Psychosocial factors associated with medication adherence in ethnically and socioeconomically diverse patients with epilepsy. Epilepsy Behav. 2015;46:242-245.

56. Marzec LN, Maddox TM. Medication adherence in patients with diabetes and dyslipidemia: associated factors and strategies for improvement. Curr Cardiol Rep. 2013;15(11):1-8. 
57. Paschal AM, Rush SE, Sadler T. Factors associated with medication adherence in patients with epilepsy and recommendations for improvement. Epilepsy Behav. 2014;31:346-350.

58. Sacks NC, Burgess JF, Cabral HJ, Pizer SD, McDonnell ME. Cost sharing and decreased branded oral anti-diabetic medication adherence among elderly part D medicare beneficiaries. J Gen Intern Med. 2013;28(7):876-885.

59. Halyard MY. The use of real-time patient-reported outcomes and qualityof-life data in oncology clinical practice. Expert Rev Pharmacoecon Outcomes Res. 2011;11(5):561-570.
60. Abernethy AP, Herndon JE, Wheeler JL, et al. Improving health care efficiency and quality using tablet personal computers to collect research-quality, patient-reported data. Health Serv Res. 2008;43(6): 1975-1991.

61. Fung V, Mangione CM, Huang J, et al. Falling into the coverage gap: part $\mathrm{D}$ drug costs and adherence for medicare advantage prescription drug plan beneficiaries with diabetes. Health Serv Res. 2010;45(2):355-375.

62. Sheingold S. Impacts of generic competition and benefit management practices on spending for prescription drugs: evidence from medicare's part D benefit. Medicare Medicaid Res Rev. 2014;4(1):E1-E13. 


\section{Supplementary materials \\ Additional survey details}

The survey was administered on an Apple iPad2 (Apple, Cupertino, CA, USA), with a plastic cover to allow for easy grip and identification in the busy outpatient setting of a major academic neurology clinic. The survey questions were built using the Tonic for Health platform (Tonic Solutions Inc., CA, USA), a survey software tool that allowed intuitive survey construction, and integration with the Apple iPad iOS (version 8 and beyond) and the hospital's electronic health record (EHR). All data were stored in a repository compliant with the hospital's privacy policies.

In addition to the measures described in the main manuscript, we also collected the NIH PROMIS-10. The NIH PROMIS-10 is a short form that measures a patient's perceived physical and mental health. The PROMIS-10 has been validated in populations with different neurological diseases (eg, stroke, epilepsy, and Parkinson's disease) as well as without neurological diseases and attempt to measure patient-reported physical and mental function. ${ }^{1}$

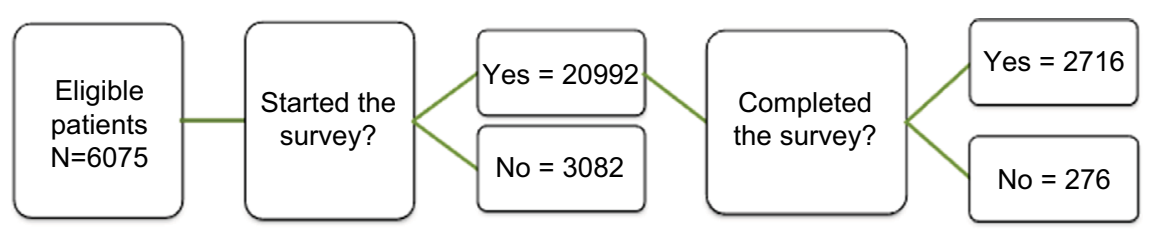

Figure SI Survey attrition.

Note: It demonstrates the attrition from 6075 to 2716 patients.

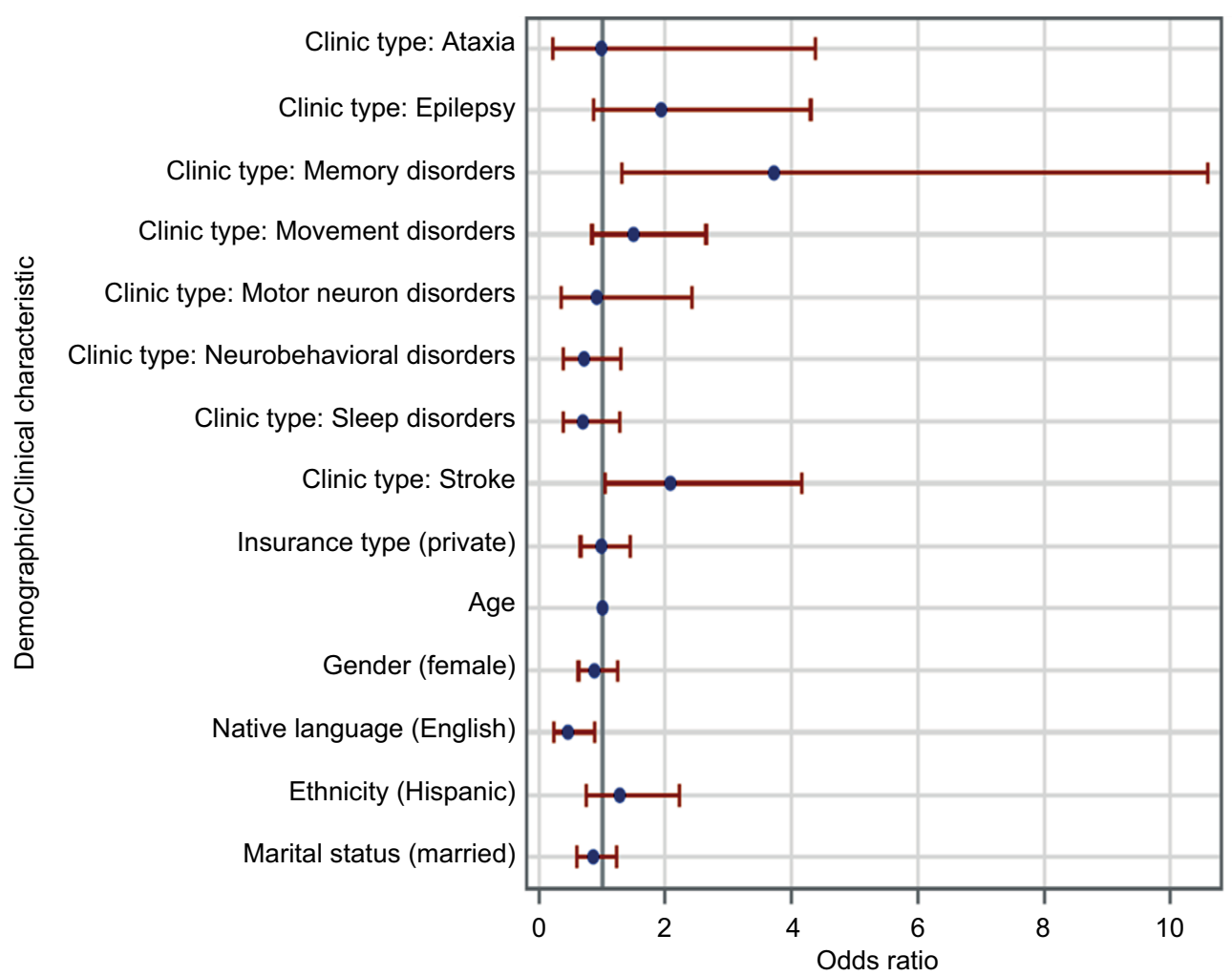

Figure S2 Demographic and clinical predictors of cost-related medication nonadherence.

Notes: It graphically represents the logistic regression using demographic and clinical characteristics in the model to predict the odds of cost-related medication nonadherence. Red line represent 95\% Cls. The patients whose preferred language was English (OR: 0.46 [0.25-0.87]), the patients seen at the memory disorders clinic (OR: 3.72 [1.3-10.6]), and the patients seen at the stroke clinic (OR: 2.I [I.0-4.2]) had higher odds for reporting cost-related medication nonadherence.

Abbreviations: $\mathrm{Cl}$, confidence interval; OR, odds ratio. 
Table SI Characteristics of the eligible population by survey participation

\begin{tabular}{|c|c|c|c|}
\hline & \multicolumn{2}{|c|}{ Survey participation } & \multirow[t]{2}{*}{$\overline{p \text {-Value }}$} \\
\hline & $\begin{array}{l}\text { No, } \mathbf{N} \\
\text { (Column \%) }\end{array}$ & $\begin{array}{l}\text { Yes, } \mathbf{N} \\
\text { (Column \%) }\end{array}$ & \\
\hline Total, $\mathrm{n}=6075$ & 3082 & 2992 & \\
\hline Mean age (years $\pm S D$ ) & $57 \pm 19$ & $56 \pm 18$ & 0.0260 \\
\hline Gender & & & 0.6676 \\
\hline Male, $n=278$ I & 1403 (45.52) & $1387(45.48)$ & \\
\hline Female, $n=3292$ & $1679(54.48)$ & $1613(53.93)$ & \\
\hline Ethnicity & & & 0.1357 \\
\hline Non-Hispanic, $n=3354$ & $1677(88.92)$ & $1677(90.40)$ & \\
\hline Hispanic, $n=387$ & $209(11.08)$ & $178(9.60)$ & \\
\hline Preferred language & & & $<0.0001$ \\
\hline English, $n=5624$ & $2805(90.98)$ & $2819(94.22)$ & \\
\hline Non-English, $n=45$ I & $278(9.02)$ & $173(5.78)$ & \\
\hline Insurance & & & $<0.0001$ \\
\hline Medicare, Medicaid, and MassHealth, $\mathrm{n}=2391$ & $1369(44.40)$ & $1022(34.16)$ & \\
\hline Private, $n=3684$ & $17 \mid 4(55.60)$ & $1970(65.84)$ & \\
\hline Marital status & & & 0.0069 \\
\hline Single, $\mathrm{n}=2510$ & $1307(45.70)$ & $1203(42.15)$ & \\
\hline Married, partnered, $\mathrm{n}=3204$ & $1553(54.30)$ & I65I (57.85) & \\
\hline Clinic type & & & $<0.0001$ \\
\hline Ataxia, $n=117$ & $82(2.66)$ & $35(1.17)$ & \\
\hline Epilepsy, $n=520$ & $327(10.6 \mathrm{I})$ & $193(6.45)$ & \\
\hline General neurology, $n=2489$ & I I 68 (37.89) & $|32|(44.15)$ & \\
\hline Memory, $n=473$ & $222(7.20)$ & 251 (8.39) & \\
\hline Movement, $n=1057$ & $584(18.94)$ & $473(15.81)$ & \\
\hline Neuromuscular, $\mathrm{n}=291$ & $232(7.53)$ & $59(1.97)$ & \\
\hline Neurobehavioral, $\mathrm{n}=376$ & $202(6.55)$ & $174(5.82)$ & \\
\hline Sleep, $n=224$ & $0(0)$ & 224 (7.49) & \\
\hline Stroke, $n=528$ & $266(8.63)$ & $262(8.76)$ & \\
\hline
\end{tabular}

Notes: Two-sided $t$-tests were used to calculate $p$-values to compare the mean values of patient age between the groups. The chi-squared test of independence was used to calculate the $p$-values to test whether the categorical variables were associated with increased rates of adherence.

\section{Reference}

1. Hays RD, Bjorner JB, Revicki DA, Spritzer KL, Cella D. Development of physical and mental health summary scores from the patient-reported outcomes measurement information system (PROMIS) global items. Qual Life Res. 2009;18:873-880.

\section{Publish your work in this journal}

ClinicoEconomics and Outcomes Research is an international, peerreviewed open-access journal focusing on health technology assessment, pharmacoeconomics and outcomes research in the areas of diagnosis, medical devices, and clinical, surgical and pharmacological intervention. The economic impact of health policy and health systems organization also constitute important areas of coverage. The manuscript management system is completely online and includes a very quick and fair peer-review system, which is all easy to use. Visit http://www.dovepress.com/testimonials.php to read real quotes from published authors. 